Island Studies Journal, Vol. 9, No. 2, 2014, pp. 383 - 384

\title{
A Response to Armstrong and Read, Poirine and Bertram
}

\author{
Jerome L. McElroy \\ Saint Mary's College \\ Notre Dame, IN \\ USA \\ jmcelroy@saintmarys.edu
}

\begin{abstract}
This is a brief response to Armstrong and Read, Poirine, and Bertram, synthesizing their welcome thoughtful remarks in response to my paper, and briefly outlining the way forward that research in this area of island studies could take.
\end{abstract}

Keywords: development, geography, island, great circle distance, gravity models, tourism, welfare

(C) 2014 - Institute of Island Studies, University of Prince Edward Island, Canada.

\section{Introduction}

All three rejoinders - by Armstrong and Read, Poirine and Bertram - provide a firm platform for embarking on further empirical exploration as well as for enriching our understanding of geography's role in island welfare.

\section{Armstrong and Read}

In the first case, Armstrong and Read have argued persuasively for using the non-linear log form of the Great Circle Distance variable - instead of the absolute form employed in McElroy \& Lucas - to measure distance in order to more accurately account for the lumpiness in long-haul transport costs characteristic of islands as well the phenomenon of distance decay. The authors also offer future researchers an array of intervening variables that may offset the influence of distance. These include the relative prosperity of the region where the island is located and the number/size of islands competing in the cluster, the types of tourism under examination (cruise, stay over, etc.), and the potential influence of colonial history, politics, culture and language. But, by and large, Armstrong and Read agree that geographical accessibility is, if "not the key determinant ... it must surely be ... one of the two or three principle influences on [insular] economic performance."

\section{Poirine}

In the second case, Poirine demonstrates how gravity models can be used to capture geographic impacts, that is, the inverse relation between trade and distance. Using a gravity model of tourism demand, he reports on his 2010 research co-authored with Dropsy and Montet which suggests that tourism receipts per capita are inversely related to remoteness. Following Armstrong and Read's suggestion that culture and political history mitigate the effects of distance, the same 2010 study actually measured the favorable impact on the 


\section{J. L. McElroy}

number of tourists - irrespective of distance - of the same host-guest language, currency and colonial past. In addition, Poirine provides an alternative theoretical explanation other than the simple distance decay argument for the effect of distance on insular living standards. Transport costs raise the prices of inputs and capital, reduce net value added per worker, and hence lower living standards. Poirine's rejoinder illustrates that geographical accessibility research is well under way.

\section{Bertram}

In the third case, Bertram has pointed up some of the potential weaknesses in our initial study, and he has also addressed some the of wider, long-run research issues surrounding the impact of political affiliation. Clearly anyone doing multivariate analysis with the small-island data set knows from experience that results are often materially affected by what Bertram calls "sample selection bias." This is one reason why we called the original study a provisional note. The sample size of 35 is certainly a limitation that calls for further exploration. In addition, the fact that tourism did not show up as a major determinant of island welfare could in part be due to the somewhat amorphous variable employed, i.e. services as a percent of GDP. Perhaps a more exact measure like the total contribution of tourism to GDP (WTTC, 2014) would yield more satisfactory results.

\section{Conclusion: beckoning research}

Finally, regarding the impact of political affiliation on the long-term prosperity of nonsovereign islands, the McElroy \& de Albuquerque (1995) conclusion that the dependencies were economic backwaters in the immediate postwar era was based on the fragmentary evidence then existing. The increasing availability of more extensive time-series will determine whether it will stand the test of time. In the meanwhile, Bertram will likely be at the forefront of this important historical research, as his rejoinder amply illustrates.

\section{References}

McElroy, J.L., \& de Albuquerque, K. (1995). The social and economic propensity for political dependence in the insular Caribbean. Social and Economic Studies, 44(1), 167-193.

World Travel and Tourism Council. (2014). Economic impact research: Country reports. London: WTTC. Retrieved from http://www.wttc.org/research/economic-impact-research/ 